\section{International Scientific Journal Theoretical \& Applied Science}

\author{
p-ISSN: 2308-4944 (print) ｅ-ISSN: 2409-0085 (online) \\ Year: 2015 Issue: 12 Volume: 32
}

Published: $30.12 .2015 \quad \underline{\text { http://T-Science.org }}$

SECTION 23. Agriculture. Agronomy. The technique.
Galymzhan Aldabergenovich Yussupov

Master of technical sciences, Teacher of the department «Technology of food products, processing industries and biotechnology» M.Kh. Dulaty Taraz State University, Kazakhstan jiboj@mail.ru

Bahyt Amirovich Sauir Master of technical sciences, Senior lecturer of the department Technology of food products, processing industries and biotechnology» M.Kh. Dulaty Taraz State University, Kazakhstan

\title{
EFFECT OF LIGHT ON ANTHOCYANINS' APPLES
}

Abstract: The article presents the results of changes in brightness of apples. After 72 hour of light the $L^{*}$ (lightness) of apples has changed 73.02 to 51.60.

Scale $a^{*}$ shows opponent red-green color. Thus Redness is positive versus Greenness is negative. The measurements of $a^{*}$ has changed after 72 hours from -5.77 until 20.32 .

The other opponent color axis, $b^{*}$, is positive for yellow color and negative for blue color. The yellow color for Johnatan has decreased after light treatment from 34.18 until 22.27 after 72 hours.

Key words: apples; fruit color; post-harvest.

Language: Russian

Citation: Yussupov GA, Sauir BA (2015) EFFECT OF LIGHT ON ANTHOCYANINS' APPLES. ISJ Theoretical \& Applied Science 12 (32): 122-125.

Soi: http://s-o-i.org/1.1/TAS-12-32-24 Doi: crossef http://dx.doi.org/10.15863/TAS.2015.12.32.24

\section{ВЛИЯНИЕ СВЕТА НА АНТОЦИАНЫ ЯБЛОК}

Аннотация: В статье приведены результаты изменения света (яркости) яблок. После 72 часа света $L$ * (яркость) яблок изменилось с 73.02 до 51.60.

Шкала $a^{*}$ показывает противоположность красного к зеленному иявету. Таким образом, красный ивет положительный в сравнений с зеленным. Измерения $а$ * после 72 часов излучения изменилось с -5.77 до 20.32.

Друая ось извета, б*, является положительным для желтого извета и отрицательным для синего ияета. После 72 часов излучения желтый цвет яблоки Johnatan снизилостьс 34.18 до 22.27 после 72 часов.

Ключевые слова: яблоки, иявет фруктов, урожай.

Цвет является одним из важных индикаторов в созревании и качество во многих плодах [1]. Накопление антоцианов происходит в кожуре яблок при созревании. Основными пигментами во фруктах является каротинойды и анотоцианы. Антоцианы - пигментные вещества из группы гликозидов. Они находятся в растениях, обусловливая красную, фиолетовую и синюю окраски плодов и листьев [2]. Название антоцианам дал еще в 1835 г. немецкий ученный Л. Маркварт. Необычайно красивая и разнообразная гамма расцветки антоцианов издавна привлекала внимание естествоиспытателей, пытающихся объяснить причину такой природной красоты, выделить из лепестков эти красящие вещества, которые, как было замечено, обладали способностью при определенных условиях изменять свой цвет. Свет - определяющее условие образования и накопления антоцианов для всех видов и форм растений. В условиях похоладания действие света на накопление антоцианов в растениях усиливается. Основой красной, фиолетовой, синей, бордовой, розовой окраски большинства плодов являются антоцианы [3].

Яблоки - самый первичный фрукт. Яблоки и продукты ее переработки, обладают лечебными свойствами. Антоцианы, которые накапливаются в плодах, положительно влияют на зреительный аппарат человека. Известно, что антоцианы являются:

- сильными антиоксидантами и нейтрализуют действие свободных радикалов;

- обладают противоотечным эффектом и уменьшают проницаемость капиляров;

- оказывают защитное действие на сосуды, уменьшая ломкость капилляров и оказывают 
положительный эффект при сосудистых поражениях;

- способствуют

стабилизации соединительной ткани, нормализуя отток внутриглазной жидкости при глаукоме и внутреглазное давление.

Накапливаться в кожице плодов антоцианы начинают с момента появления красной или синеватой окраски [4]. Окраска зависит от сортов яблок. Цвет плодов зависит от солнечного света.

Солнечный свет - один из наиболее важных для жизни растений экологических показателей. Он поглощается хлорофиллом и используется при построении первичного органического вещества.

Основными характеристиками света являются его спектральный состав, интенсивность, суточная и сезонная динамика.

По спектральному составу солнечный свет неоднороден. В него входят лучи, имеющие различную длину волны. Из всего спектра для жизни растений важна фотосинтетическая активная (380-710 нм) и физиологически активная радиация (300-800 нм).
Причем, наибольшее значение имеют красные (720-600 нм) и оранжевые лучи (620-595 нм). Именно они являются основными поставщиками энергии для фотосинтеза и влияют на процессы, связанные с изменением скорости развития растения (избыток красной и оранжевой составляющей спектра задерживает переход растения к цветению).

Ультрафиолетовые лучи с длиной волны 315-380 нм задерживают «вытягивание» растений и стимулируют синтез некоторых витаминов, а ультрафиолетовые лучи с длиной волны 280-315 нм повышают холодостойкость.

\section{Спектр видимого излучения}

При разложении луча белого цвета в призме образуется спектр, в котором излучения разных длин волн преломляются под разными углами. Цвета, входящие в спектр, то есть такие цвета, которые могут быть получены с помощью света одной длины волны (точнее, с очень узким диапазоном длин волн), называются спектральными цветами 5].

Основные спектральные цвета (имеющие собственное название), а также характеристики излучения этих цветов, представлены в таблице 1:

Таблица 1

Основные спектральные цвета.

\begin{tabular}{||l||c||c||c||}
\hline \multicolumn{1}{|c|}{ Цвет } & Диапазон длин волн, нм & Диапазон частот, ТГц & Диапазон энергии фотонов, эВ \\
\hline \hline Фиолетовый & $380-440$ & $680-790$ & $2,82-3,26$ \\
\hline \hline Синий & $440-485$ & $620-680$ & $2,56-2,82$ \\
\hline \hline Голубой & $485-500$ & $600-620$ & $2,48-2,56$ \\
\hline \hline Зелёный & $500-565$ & $530-600$ & $2,19-2,48$ \\
\hline Жёлтый & $565-590$ & $510-530$ & $2,10-2,19$ \\
\hline \hline Оранжевый & $590-625$ & $480-510$ & $1,98-2,10$ \\
\hline Красный & $625-740$ & $400-480$ & $1,68-1,98$ \\
\hline
\end{tabular}

Процесс созревания фруктов включает в себя серии физиологических, биохимических и органолептических изменений. Который дает фруктам желаемое качество и привлекательность[6].

\section{Цвет фруктов}

Цвет является основным индикатором качества свежих фруктов. С помощью цвета можно также определить стадию и процесс созревания фруктов. Цвет также является основным аспектом для покупателей. У цвета есть 3 основных аспекта: яркость, оттенок и красочность[7-8].

Цель. Целью нашей работы явилось изучение влияние света на антоцианы яблок.

\section{Материалы и методы.}

Эксперимент был проведен в University of Applied Sciences Weihenstephan-Triesdorf Wiedenbach, Германия. В качестве эксперимента использовали яблоки сорта Golden Delicious. Суммарное определение содержания антоцианов проводили спектрофотометрическим методом на спектрофотометре Konica Minolta 600D. Исследования количественного содержания антоцианов в плодах проводили в момент до излучения и после излучения. На яблоках была сделана метка с лицевой и обратной стороны для измерения. В качестве облучения использовались лампы (LED, УФ). Яблоки облучались в специальном боксе. Температура в боксе была $\mathrm{t}$ $+21{ }^{0} \mathrm{C} /$ +-2 ${ }^{0} \mathrm{C}$. Яблоки расположили под лампами на расстоянии 85 см. Эксперимент 


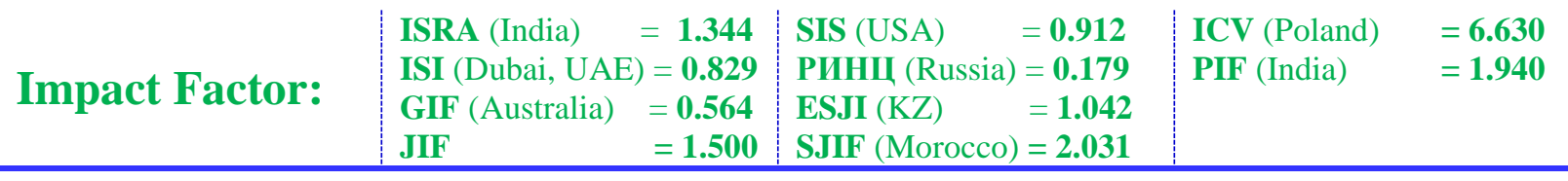

проводился 72 часа непрерывного облучения. В ходе различных экспериментов было замечено, что это самый оптимальный вариант для накопления антоцианов на яблоках сорта Golden Delicious. В следующей таблице 2 показано, как меняось цвет под воздействием LED, УФ ламп.

\section{Golden Delicious.}

Таблица 2

$\mathrm{L}$
\begin{tabular}{|l|l|l|l|l|l|l|l|l|l|l|l|}
\hline $\mathrm{t}$ & $\mathrm{A}$ & $\mathrm{B}$ & $\mathrm{C}$ & $\mathrm{D}$ & $\mathrm{E}$ & $\mathrm{F}$ & $\mathrm{G}$ & $\mathrm{H}$ & $\mathrm{I}$ & $\Delta$ & ст.откл. \\
\hline 0 & 68.52 & 74.07 & 75.79 & 72.40 & 73.42 & 68.96 & 74.30 & 72.01 & 76.78 & 73.02 & 2.80 \\
\hline 72 & 49.33 & 53.93 & 51.40 & 43.57 & 55.09 & 47.26 & 54.77 & 49.31 & 59.78 & 51.60 & 4.95 \\
\hline
\end{tabular}

$\mathrm{a}$
\begin{tabular}{|l|l|l|l|l|l|l|l|l|l|l|l|}
\hline $\mathrm{t}$ & $\mathrm{A}$ & $\mathrm{B}$ & $\mathrm{C}$ & $\mathrm{D}$ & $\mathrm{E}$ & $\mathrm{F}$ & $\mathrm{G}$ & $\mathrm{H}$ & $\mathrm{I}$ & $\Delta$ & ст.откл. \\
\hline 0 & -6.52 & -3.55 & -5.77 & -6.95 & -4.91 & -7.58 & -4.33 & -8.01 & -4.80 & -5.77 & 1.53 \\
\hline 72 & 14.04 & 19.45 & 24.12 & 25.38 & 18.15 & 20.06 & 21.03 & 21.85 & 18.79 & 20.32 & 3.35 \\
\hline
\end{tabular}

b
\begin{tabular}{|l|l|l|l|l|l|l|l|l|l|l|l|}
\hline $\mathrm{t}$ & $\mathrm{A}$ & $\mathrm{B}$ & $\mathrm{C}$ & $\mathrm{D}$ & $\mathrm{E}$ & $\mathrm{F}$ & $\mathrm{G}$ & $\mathrm{H}$ & $\mathrm{I}$ & $\Delta$ & ст.откл. \\
\hline 0 & 45.84 & 50.38 & 44.09 & 43.13 & 47.76 & 47.01 & 49.08 & 46.12 & 45.31 & 46.52 & 2.31 \\
\hline 72 & 29.78 & 37.25 & 29.84 & 21.89 & 36.38 & 28.79 & 36.22 & 31.14 & 38.68 & 32.22 & 5.38 \\
\hline
\end{tabular}

Здесь:

L (Lightness) - яркость цвета измеряется от 0 до $100 \%$;

a - диапазон цвета по цветовому кругу от зеленого -120 до красного значения +120;

b - диапазон цвета от синего -120 до желтого +120 .

Результаты и обсуждение.

Изменение цвета яблок приведены в таблице. По таблце $2 \mathrm{~L}$, a, b приведены результаты до и после облучения в течение 72 часов. После 72 часов можно наглядно увидеть накопление антоцианов на яблоках. После облучения яблоки стали красного оттенка. В таблице 3 можно увидеть как менялся цвет и при какой волне больше всего произошло изменений. Самое большое изменение произошло в длине волн 500-600 нм.

\section{Степень изменения цвета при различных волнах.}

Таблица 3

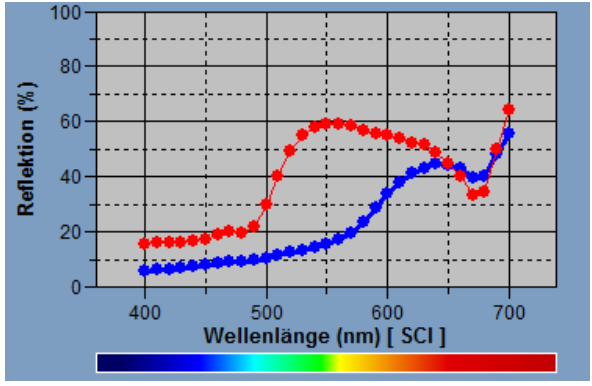

Заключение.

В результате исследований было определено накопление антоцианов на сортах яблок Golden Delicious при излучении в течение 72 часов с помощью УФ и LED ламп. Исходя из полученных данных можно делать выводы:

1) Для излучения яблок нужно брать яблоки хорошего качество без внешних повреждений.

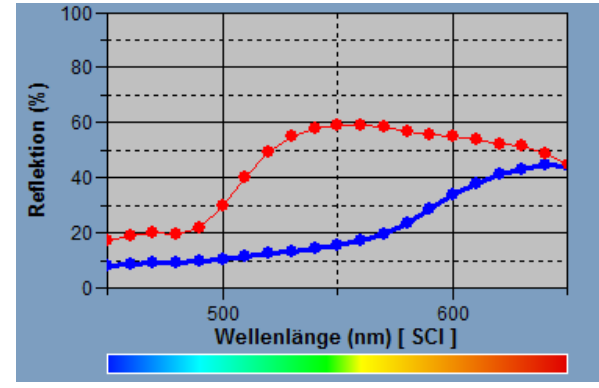

2) Для получения наилучшего результата желательно брать яблоки зеленого цвета и немножко несозревшие.

3) Высокое накопление антоцианов обнаруживается уже после 48 часов облучения. 


\begin{tabular}{l|lrl|l|ll} 
& ISRA (India) & $=\mathbf{1 . 3 4 4}$ & SIS (USA) & $=\mathbf{0 . 9 1 2}$ & ICV (Poland) & $=\mathbf{6 . 6 3 0}$ \\
Impact Factor: & ISI (Dubai, UAE) $=\mathbf{0 . 8 2 9}$ & PUHU (Russia) $=\mathbf{0 . 1 7 9}$ & PIF (India) & $=\mathbf{1 . 9 4 0}$ \\
& GIF (Australia) & $\mathbf{0 . 5 6 4}$ & ESJI (KZ) & $=\mathbf{1 . 0 4 2}$ & & \\
& JIF & $=\mathbf{1 . 5 0 0}$ & SJIF (Morocco) $=\mathbf{2 . 0 3 1}$ & &
\end{tabular}
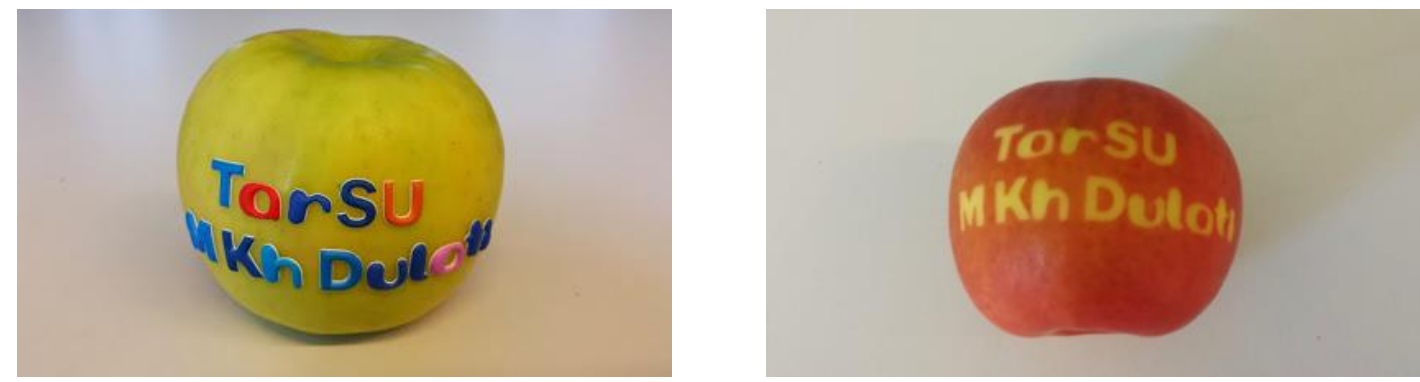

\section{References:}

1. Koes R, Verweij W, Quatrocchio F (2005) Flavonoids: A colorful model for the regulation and evolution of biochemical pathways. Trends plants sci. 2005, 10, 236-242.

2. Chub V (2008) Dlya chego nuzhny antotsiany // Tsvetovodstvo. — 2008. — № 6. - pp. 2225.

3. Kharborn DB (1968) Fenol'nye glikozidy i ikh rasprostranenie v prirode /Dzh. Kharborn // Biokhimiya fenol. soedineniy. - Moscow, 1968. - pp. 108-136.

4. Petrova VP (1986) Biokhimiya dikorastushchikh plodovo-yagodnykh rasteniy / V.P. Petrova. - K. : Vishcha shk. Golovnoe izdvo, $1986-276 \mathrm{p}$.
5. Thomas JB, Paris DN (2005) Svoronos. CRC Handbook of Fundamental Spectroscopic Correlation Charts. CRC Press, 2005.

6. Hunt RGW (2001) Measuring colour. Fountain press, London.

7. Awad MA, Wagenmakers PS, A de Jager (2001) Effects of light on flavonoid and chlorogenic acid levels in the skin of 'Jonagold' apples. Sci Hort. 2001; 88: 289-298

8. Hollman PCH, Katan MB (1999) Dietary Flavonoids: Intake, Health Effects and Bioavailability. Food and Chemical Toxicology, 37(9-10), 937-942. 